\title{
Takayasu's arteritis diagnosed in a patient with Crohn's disease: An unpredicted correlation
}

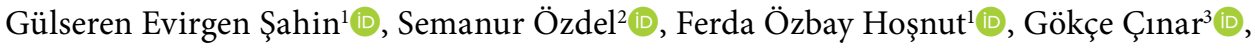 \\ Hüsniye Yücel ${ }^{4}$ (D) Meltem Akçaboy ${ }^{4}$ (D) \\ ${ }^{1}$ Department of Pediatric Gastroenterology, Dr. Sami Ulus Maternity and Children's Health and Diseases Training and Research Hospital, Ankara, Turkey \\ ${ }^{2}$ Department of Pediatric Rheumatology, Dr. Sami Ulus Maternity and Children's Health and Diseases Training and Research Hospital, Ankara, Turkey \\ ${ }^{3}$ Department of Radiology, Dr. Sami Ulus Maternity and Children's Health and Diseases Training and Research Hospital, Ankara, Turkey \\ ${ }^{4}$ Department of Pediatrics, Dr. Sami Ulus Maternity and Children's Health and Diseases Training and Research Hospital, Ankara, Turkey
}

Takayasu's arteritis (TA) and Crohn's disease (CD) are both immune-mediated, chronic, recurrent granulomatous inflammatory diseases that are rarely seen in children. ${ }^{1,2}$ Here, we present an adolescent female patient with $\mathrm{CD}$ with severe upper gastrointestinal system involvement diagnosed as TA to guide the probable common pathophysiological pathways and to remind regarding the possibility of the coexistence of these two diseases.

A 15-year-old girl was admitted to our clinic with dyspeptic complaints, diarrhea for two weeks, and weight loss. Her prenatal, natal, and postnatal history was uneventful. Her family history was unremarkable. Physical examination including growth parameters and pulses were in normal limits. Laboratory data revealed elevation of inflammatory markers. The upper endoscopy and colonoscopy presented multiple patchy and longitudinal mucosal aphthous ulcerations and cobblestone areas. Histopathological examination showed an increase of lamina propria cellularity, basal lymphoid aggregates, and epithelioid granuloma as well as crypt abscess formation. Clinical and histopathological findings were consistent with $\mathrm{CD}$. The patient was initially treated with $2 \mathrm{mg} / \mathrm{kg} /$ day oral methylprednisolone. Azathioprine was added to corticosteroid therapy in follow-up. The corticosteroid therapy was tapered by the remission in third week. Over the course of two months, disease activity was unapparent with normal acute phase reactants. At the eighth month follow-up, acute phase indicators started to increase (erythrocyte sedimentation rate: $80 \mathrm{~mm} / \mathrm{h}$, C-reactive protein: $92 \mathrm{mg} / \mathrm{dL}$ ) in routine controls without any symptoms. All of the results were in normal ranges for the complete blood count, autoimmune markers, and endoscopic findings excluding disease activity. The patient had constitutional symptoms with unilateral neck pain with widespread sensitivity. Neck ultrasound revealed a stenosis of the right carotid artery. The magnetic resonance angiography imaging for right carotid artery showed diffuse wall thickening and 30-40\% stenosis extending to the level of bifurcation

Received: January 20, 2020 Accepted: January 26, 2020 Published online: June 25, 2020

Correspondence: Meltem Akçaboy, MD. SBÜ Ankara Dr. Sami Ulus Kadın Doğum, Çocuk Sağlığı ve Hastalıkları Eğitim ve Araştırma Hastanesi Çocuk Sağlığı ve Hastalıkları Kliniği. 06080 Altındağ, Ankara, Türkiye. Tel: +90 532 - 6476997 e-mail: meltemileri@yahoo.com

\section{Citation:}

Evirgen Şahin G, Özdel S, Özbay Hosnut F, Çınar G, Yücel H, Akçaboy M. Takayasu's arteritis diagnosed in a patient with Crohn's disease: An unpredicted correlation. Arch Rheumatol 2021;36(1):135-137.

This is an open access article under the terms of the Creative Commons Attribution-NonCommercial License. which permits use. distribution and reproduction in any medium. provided the original work is properly cited and is not used for commercial purposes (http://creativecommons.org/licenses/by-nc/4.0/). 

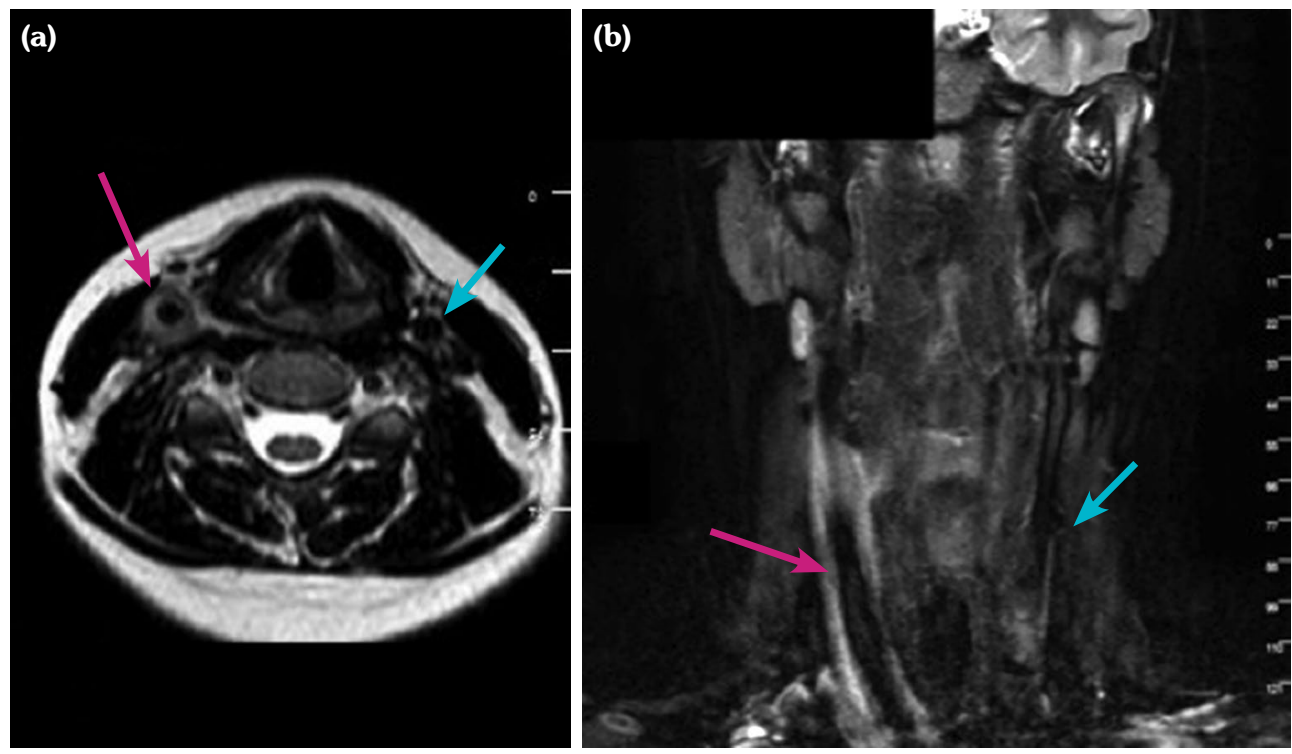

Figure 1. (a) Axial T2-weighted magnetic resonance angiography image for right carotid artery (red arrow) compared to left (blue arrow) showing diffuse wall thickening. (b) Coronal T2-weighted magnetic resonance angiography image for right carotid artery (red arrow) showing diffuse wall thickening and stenosis extending to level of bifurcation comparing to left (blue arrow).

(Figure 1). Clinical and laboratory features were consistent with TA. A written informed consent was obtained from the ethics committee and the parents of the patient.

Crohn's disease and TA are both chronic granulomatous diseases with a course of remission and relapses. The coexistence of these two diseases rather than coincidence is associated with common features in etiopathogenesis. ${ }^{3-5}$ The inflammation process is conducted by the similar cytokines like tumor necrosis factor-alpha and interleukin (IL)- 6 in both diseases. ${ }^{4,5}$ The fact that $\mathrm{p} 40$, the product of IL-12 associated with TA, is a subgroup of IL-23, one of the genes implicated in the pathogenesis of $\mathrm{CD}$, suggests that both diseases have common genetic characteristics. ${ }^{5}$ Granulomatous reaction and mononuclear inflammation are common histopathological features of both diseases., ${ }^{4,5}$ Until now, few case reports have reported $\mathrm{TA}$ and $\mathrm{CD}$ in the same patient, though such coexistence has been hypothetically predicted to occur in only one in 10 billion individuals..$^{6,7}$ Primarily, it is important to be careful in terms of extra-intestinal involvement in $\mathrm{CD}$ and the findings of other autoimmune diseases in terms of the course of the disease and prevention of complications. Surely, TA, which is a rare association, should also be kept in mind in the presence of unexplained findings and non-symptomatic acute flares in patients with $\mathrm{CD}$ during the remission of the disease.

\section{Declaration of conflicting interests}

The authors declared no conflicts of interest with respect to the authorship and/or publication of this article.

\section{Funding}

The authors received no financial support for the research and/or authorship of this article.

\section{REFERENCES}

1. Lavie G, Zalmanovich A, Golan Y, Jonas Kimchi $\mathrm{T}$, Barenboim E. Acute stroke revealing Takayasu's arteritis in a patient with Crohn's disease. Acta Clin Belg 2016;71:250-2.

2. Tung Chen Y, Todoli Parra JA, Iborra Colomino M, Moll Guillen JL, Martin Abad LJ, Garcia Marcos R, et al. Takayasu's arteritis associated with Crohn's disease. Rev Clin Esp 2014;214:e37-40.

3. Kusunoki R, Ishihara S, Sato M, Sumita Y, Mishima Y, Okada M, et al. Rare case of Takayasu's arteritis 
associated with Crohn's disease. Intern Med 2011;50:1581-5.

4. Yassinger S, Adelman R, Cantor D, Halsted CH, Bolt RJ. Association of inflammatory bowel disease and large vascular lesions. Gastroenterology 1976;71:844-6.

5. Saruhan-Direskeneli G, Hughes T, Aksu K, Keser G, Coit P, Aydin SZ, et al. Identification of multiple genetic susceptibility loci in Takayasu arteritis. Am J
Hum Genet 2013;93:298-305.

6. Taddio A, Maschio M, Martelossi S, Barbi E, Ventura A. Crohn's disease and Takayasu's arteritis: an uncommon association. World J Gastroenterol 2013;19:5933-5.

7. Yilmaz N, Can M, Alibaz-Oner F, Direskeneli $\mathrm{H}$. Clinically silent Crohn's disease in a patient with Takayasu's arteritis unresponsive to conventional therapies. Rheumatol Int 2013;33:3091-3. 